\title{
Erratum to: Recent Progress to Understand and Improve Zeolite Stability in the Aqueous Medium
}

\author{
Sebastian Prodinger ${ }^{a, *}$ and Miroslaw A. Derewinski ${ }^{b, c, * *, * * *}$ \\ ${ }^{a}$ University of Delaware, Newark, Delaware, 19711 USA \\ ${ }^{b}$ Institute of Integrated Catalysis, Pacific Northwest National Laboratory, Richland, 99352 USA \\ ${ }^{c}$ Jerzy Haber Institute of Catalysis and Surface Chemistry, Polish Academy of Sciences, Krakow, 30239 Poland \\ *e-mail:sproding@udel.edu \\ **e-mail: miroslaw.derewinski@pnnl.gov \\ ***e-mail:ncderewi@cyf-kr.edu.pl
}

Received September 10, 2021; revised September 13, 2021; accepted September 13, 2021

DOI: $10.1134 / \mathrm{S} 0965544121090176$

The article "Recent Progress to Understand and Improve Zeolite Stability in the Aqueous Medium", written by Sebastian Prodinger and Miroslaw A. Derewinski, was originally published electronically in Springer-Link on 6 May 2020 without Open Access. After publication in volume 60, issue 4, pages 420-436 the authors decided to make the article an Open Access publication. Therefore, the copyright of the article has been changed to (C) The Author(s) 2021 and the article is forthwith distributed under the terms of a Creative Commons Attribution 4.0 International License (http://creativecommons.org/licenses /by/4.0/, CC BY), which permits use, duplication, adaptation, distribution and reproduction of a work in any medium or format, as long as you cite the original author(s) and publication source, provide a link to the Creative Commons license, and indicate if changes were made.

The original article can be found online at https://doi.org/10.1134/S0965544120040143 